\title{
Deployable nuclear fleet based on available quantities of uranium and reactor types - the case of fast reactors started up with enriched uranium
}

\author{
Anne Baschwitz ${ }^{*}$, Gilles Mathonnière, Sophie Gabriel, and Tommy Eleouet \\ CEA, DEN/DANS/I-tésé, 91191 Gif-sur-Yvette, France
}

Received: 19 October 2015 / Received in final form: 11 January 2016 / Accepted: 19 January 2016

Published online: 18 March 2016

\begin{abstract}
International organizations regularly produce global energy demand scenarios. To account for the increasing population and GDP trends, as well as to encompass evolving energy uses while satisfying constraints on greenhouse gas emissions, long-term installed nuclear power capacity scenarios tend to be more ambitious, even after the Fukushima accident. Thus, the amounts of uranium or plutonium needed to deploy such capacities could be limiting factors. This study first considers light-water reactors (LWR, GEN III) using enriched uranium, like most of the current reactor technologies. It then examines the contribution of future fast reactors (FR, GEN IV) operating with an initial fissile load and then using depleted uranium and recycling their own plutonium. However, as plutonium is only available in limited quantity since it is only produced in nuclear reactors, the possibility of starting up these Generation IV reactors with a fissile load of enriched uranium is also explored. In one of our previous studies, the uranium consumption of a third-generation reactor like an $\mathrm{EPR}^{\mathrm{TM}}$ was compared with that of a fast reactor started up with enriched uranium (U5-FR). For a reactor lifespan of 60 years, the U5FR consumes three times less uranium than the EPR and represents a $60 \%$ reduction in terms of separative work units (SWU), though its requirements are concentrated over the first few years of operation. The purpose of this study is to investigate the relevance of U5-FRs in a nuclear fleet deployment configuration. Considering several power demand scenarios and assuming different finite quantities of available natural uranium, this paper examines what types of reactors must be deployed to meet the demand. The deployment of light-water reactors only is not sustainable in the long run. Generation IV reactors are therefore essential. Yet when started up with plutonium, the number of reactors that can be deployed is also limited. In a fleet deployment configuration, U5FRs appear to provide the best solution for using uranium, even if the economic impact of this consumption during the first years of operation is significant.
\end{abstract}

\section{Introduction}

At the current rate at which fuel is consumed, the natural uranium resources identified so far will be sufficient to meet our needs for the next 100 years [1]. However, most organisations in charge of defining energy-related scenarios consider a considerable increase in international nuclear power generation to meet the significantly increasing global energy demand, as well as to comply with climate constraints to reduce greenhouse gas emissions. Due to the growing nuclear reactor fleet in many countries, it is assumed that resources will therefore be depleted more rapidly.

Within the scope of this study, we therefore selected various global nuclear power deployment scenarios.

\footnotetext{
* e-mail: anne.baschwitz@cea.fr
}

These scenarios have been applied to analyse what type of reactors must be deployed to meet the global demand: light-water reactors (LWR) using uranium-235 $\left({ }^{235} \mathrm{U}\right)$ or fast reactors (FR) using uranium-238. However, a sufficient amount of plutonium is required to start up FRs and plutonium is produced in water reactors such as pressurised water reactors (PWR) $(\approx 1 \%$ of the mass of spent fuel). In the event that no $\mathrm{Pu}$ is available, the only solution is to start up FRs with uranium enriched in ${ }^{235} \mathrm{U}$ (U5-FR).

This paper first reviews the static comparison of the total uranium consumption of a LWR with an U5-FR. We then analyse the advantages provided by such reactors within a nuclear reactor fleet development configuration.

Therefore, the first part of this paper assesses the quantities of uranium consumed for the different scenarios under investigation and according to the reactor types being developed. 
In the second part of this paper, different limits are imposed on the global uranium supply in order to clearly define the issues related to the necessary resources. The type of reactor required to meet the demand is clearly stated for each limit and each scenario.

\section{Study conditions}

\subsection{Prospective scenarios [2]}

To carry out this prospective study, we needed to define assumptions with respect to the evolving energy demand and the deployable nuclear technologies available within the century. These assumptions are detailed below.

In the energy field, needs must be defined several years in advance or even several decades in advance so as to plan the construction of infrastructures and meet the demand. This forward-looking approach particularly applies to nuclear power: firstly, because a reactor is designed to operate for about 60 years; secondly, because waste management issues, like partitioning and transmutation, must be assessed.

The "Global Energy Perspective 1998" [3] was a fiveyear study conducted jointly by the International Institute for Applied Systems Analysis (IIASA) and the World Energy Council (WEC). The goals were to examine longterm energy perspectives, their constraints, and opportunities by formulating scenarios. There are six scenarios grouped into three cases, Cases A, B, and C, providing the energy mix forecast over the 21st century.

We chose four of them (Fig. 1):

- A2 is a strong global growth scenario of around $2.7 \%$ per year, with the preferred short-term use of oil and gas resources. Nuclear energy represents $4 \%$ of world energy demand in 2050 and $21 \%$ in 2100 ;

- A3 is also a strong global growth scenario with a more gradual introduction of nuclear energy than in scenario A2; nuclear energy represents around $11 \%$ of world energy demand in 2050 and $22 \%$ in 2100 ;

- B is a business-as-usual world growth scenario during the 21 st century (around $2 \%$ per year);

- $\mathrm{C} 2$ is a scenario that has strong intentions to protect the environment against global warming. It corresponds to a low global demand, though nuclear energy represents around $12 \%$ of world demand for primary energy in 2050; this is almost twice as much as it represents today.

The IIASA scenarios consider a strong increase in the world demand in primary energy. Even if the nuclear power share is less than $20 \%$, it supposes a rather significant increase in the nuclear installed capacity.

\subsection{GRUS model}

The GRUS ${ }^{1}$ model using STELLA [4] software was developed to calculate nuclear power configurations within

\footnotetext{
${ }^{1}$ GRUS is a French abbreviation which translates as "uranium resource management with STELLA software".
}

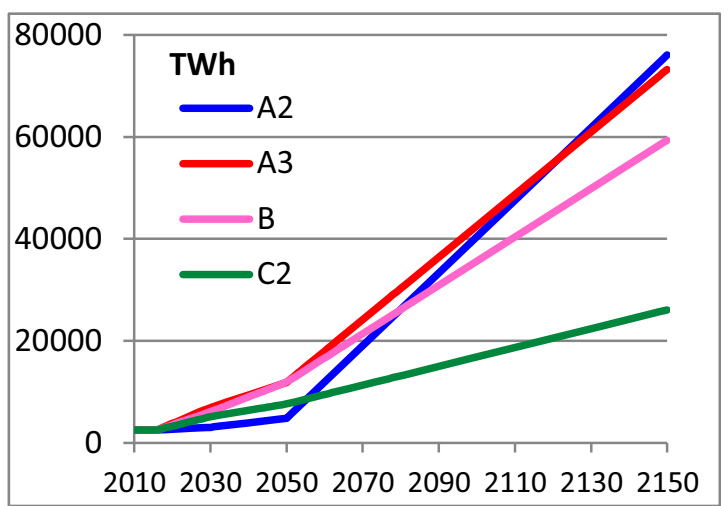

Fig. 1. IIASA scenarios: requested electronuclear generation.

various electricity demand scenarios while taking into account the complexity of the nuclear system (large number of stocks, flows and variables, numerous interactions, time scales, and different reactor technologies).

In the model, we defined:

- initial conditions (raw material stocks, kind and number of reactors and the capacities of facilities);

- key parameters (facility unit costs, cost of resources, reactor investment and operating costs, and technical characteristics of reactors);

- electricity demand versus time.

The simulation determined the nuclear fleet required to meet the yearly electricity demand according to the available resources and diverse costs.

\subsection{Reactor types}

Four types of reactors were considered in this study:

- PWRs, which are representative of the current reactors in service (GEN II);

- EPRs ${ }^{\mathrm{TM}}$ (Evolutionary Power Reactors), which are representative of Generation III water reactors (GEN III);

- FRs, which are representative of Generation IV fast reactors (GEN IV) for which a standard start-up with a $\mathrm{Pu}$ load $(\mathrm{Pu}-\mathrm{FR})$ is possible. It will also be possible to start them up with enriched uranium if no $\mathrm{Pu}$ is available (U5-FR). After several years, such reactors will become identical to reactors started up with $\mathrm{Pu}$, once they will have produced the $\mathrm{Pu}$ required for their operation.

\subsubsection{Technical characteristics}

Table 1 lists the reactor characteristics that were taken into consideration. U5-FRs have the same characteristics as $\mathrm{Pu}$ FRs in terms of power, load factor and burn-up due to the fact that they become $\mathrm{Pu}$-FRs after ten years.

Our reactors are generic reactors of large size. For the FRs, considering the characteristics we have chosen $(\mathrm{Pu}$ in core and breeding gain range), we can say it is like an SFR with an oxide fuel [5].

Table 2 compares ${ }^{235} \mathrm{U}$ requirements for EPRs and U5FRs. 
Table 1. Reactor characteristics.

\begin{tabular}{|c|c|c|c|c|}
\hline & \multirow[t]{2}{*}{ PWR } & \multirow[t]{2}{*}{$\mathrm{EPR}$} & \multicolumn{2}{|c|}{ FR } \\
\hline & & & $\mathrm{BG}=0$ & $\mathrm{BG}=0.2$ \\
\hline Gross electrical output (GWe) & 1.01 & 1.62 & & \\
\hline Efficiency (\%) & 33 & 36 & & \\
\hline Burn-up rate $(\mathrm{GWd} / \mathrm{t})$ & 45 & 60 & & \\
\hline Mass of heavy metal in core $(t)$ & 81 & 126 & & \\
\hline Load factor $(\%)$ & 77 & 90 & & \\
\hline Enrichment in ${ }^{235} \mathrm{U}(\%)$ & 3.7 & 4.9 & & \\
\hline $\mathrm{Pu}$ in core $(\mathrm{t})$ & - & - & & \\
\hline$\% \mathrm{Pu}$ in spent fuel $(\%)$ & 1.17 & 1.34 & 23.5 & 28.2 \\
\hline
\end{tabular}

BG: breeding gain.

Table 2. ${ }^{235} \mathrm{U}$ requirements.

\begin{tabular}{lllc}
\hline & Unit & EPR-type PWR & U5-FR [6] \\
\hline${ }^{235} \mathrm{U}$ enrichment & $\%$ & 4.9 & 14.4 \\
Mass of ${ }^{235} \mathrm{U}$ in core & Tonnes of ${ }^{235} \mathrm{U} / \mathrm{GWe}$ & 3.9 & 8 \\
Reloading & Tonnes of ${ }^{235} \mathrm{U} / \mathrm{GWe} /$ year & 0.78 & $1.4^{\mathrm{b}}$ \\
\hline
\end{tabular}

${ }^{a}$ We chose the characteristics of the EPR for comparison with an SR (assumptions may differ in relation to Ref. [6]). The figures are given in relation to an equilibrium cycle.

${ }^{b}$ For the first 5 reloads of an U5-FR. The U5 enrichment is given for the first core: it constantly decreases as the U5-FR becomes a Pu-FR.

\subsubsection{Assumptions for introducing fast reactors}

In the model, only PWRs are deployed up to 2040. Thereafter, different assumptions were applied when introducing new reactors:

- all new reactors are still PWRs (EPR-type) for the whole century with the once-through option;

- fast reactors (FRs) are installed as long as plutonium is available. When plutonium is not available, either PWRs or FRs started up with enriched uranium can be installed.

\section{Uranium consumption}

\subsection{Consumption comparisons for PWRs and U5-FRs}

Certain results presented during the FR13 [7] conference are recalled in this section.

In this specific case, we have considered an electric utility intending to build a FR without a sufficient amount of $\mathrm{Pu}$. At present, the electric utility can decide whether to build a PWR or a FR started up with enriched uranium. At the end of the reactor's service life (60 years), it can be considered in both cases that the electric utility will have a sufficient amount of $\mathrm{Pu}$ to start-up a new FR. The necessary amount of $\mathrm{Pu}$ corresponds to two cores: the first core and an equivalent quantity for the first few reloads until $\mathrm{Pu}$ from the first core is extracted and recycled for the following loads.

Choosing either reactor will lead to the development of next generation of FRs.

Here, we have considered an open-cycle EPR with the first core and annual reloads using enriched uranium.

We considered that reloads for a U5-FR were performed on a $1 / 5$ basis as the remaining fuel stays in the core for slightly more than 5 years. It is assumed that the cycle lasts 5 years (cooling time after unloading until the manufacture of a new sub-assembly, which can be loaded into the reactor). Enriched uranium must therefore be provided for the first core and the first 5 reloads as the following reloads will be done with the $\mathrm{Pu}$ produced by the FR.

Table 3 specifies the material flows for the different stages of the fuel cycle under consideration, as well as the enrichment requirements for the reactor lifespan when the price of natural uranium is of $€ 100 / \mathrm{kg}$ for the reactor's entire service life (flows vary depending on the price of natural uranium through optimisation of the tails assay, with $U_{\text {nat }}$ at $€ 100 / \mathrm{kg}$, the optimised content of depleted uranium is $0.23 \%$ of ${ }^{235} \mathrm{U}$ ). Year 0 corresponds to the year the reactor is commissioned.

Over the reactor's 60-year lifespan, it can be seen that the U5-FR uses three times less uranium than the EPR and requires $60 \%$ fewer SWUs. Yet, if we compare the fuel requirements over the first 7 years of operation, 
Table 3. Annual flow of materials (tonnes) and enrichment requirements (million SWU) for $1 \mathrm{GWe}$.

\begin{tabular}{|c|c|c|c|c|c|c|}
\hline \multirow[b]{2}{*}{ Year } & \multicolumn{3}{|c|}{ EPR } & \multicolumn{3}{|c|}{ FR } \\
\hline & $\begin{array}{l}\text { Flow of natural } \\
\text { uranium }\end{array}$ & MSWU & $\begin{array}{l}\text { Flow of uranium } \\
\text { enriched at } 4.9 \%\end{array}$ & $\begin{array}{l}\text { Flow of natural } \\
\text { uranium }\end{array}$ & MSWU & $\begin{array}{l}\text { Flow of uranium } \\
\text { enriched at } 14.4 \%\end{array}$ \\
\hline-2 & 769 & 0.65 & & 1,628 & 1.67 & \\
\hline-1 & 154 & 0.13 & 80 & 293 & 0.30 & 56 \\
\hline 0 & 154 & 0.13 & 16 & 293 & 0.30 & 10 \\
\hline 1 & 154 & 0.13 & 16 & 293 & 0.30 & 10 \\
\hline 2 & 154 & 0.13 & 16 & 293 & 0.30 & 10 \\
\hline 3 & 154 & 0.13 & 16 & 293 & 0.30 & 10 \\
\hline 4 & 154 & 0.13 & 16 & 161 & 0.17 & 10 \\
\hline 5 & 154 & 0.13 & 16 & & & 6 \\
\hline $\begin{array}{l}6 \text { to } 57 \\
58 \\
59\end{array}$ & 154 & 0.13 & 16 & & & \\
\hline Total & 9,844 & 8.27 & 1,019 & 3,256 & 3.34 & 111 \\
\hline
\end{tabular}

the U5-FR uses twice as more natural uranium and 2.5 times more SWUs than the EPR.

\subsection{Uranium consumption of a global nuclear reactor fleet}

This section compares the global uranium consumption for meeting the different nuclear power demand scenarios described in Section 2.1 according to the reactors being considered. We have already shown that the nuclear industry cannot entirely rely on LWRs [8]. However, the amount of plutonium available for developing the fourth generation of reactors is also a limiting factor [9].

Until 2040, only GEN III reactors are deployed, as it is considered that GEN IV reactors will only be technically available as from that date. After, two cases were considered:

- case 1 in blue: as many Pu-FRs as possible are installed depending on $\mathrm{Pu}$ availability and the fleet is then completed with EPRs;

- case 2 in red: as many Pu-FRs as possible are installed and the fleet is then completed with FRs started up with enriched uranium.

Fast reactors can be self-sufficient reactors (solid line curves) or breeder reactors with a regeneration gain of 0.2 (dotted line curves).

Figure 2 indicates the accumulated uranium consumption for scenario A3.

In Figure 3, we have added "committed uranium" to the consumed uranium, i.e. uranium for the future reloading of reactors which are currently in operation.

It has been observed that by favouring U5-FRs with respect to LWRs, it is possible to practically halve the total consumption of uranium in 2150 . With breeder reactors, it is even possible to stabilise the overall uranium consumption. A sufficient amount of $\mathrm{Pu}$ is therefore available to only develop Pu-FRs.

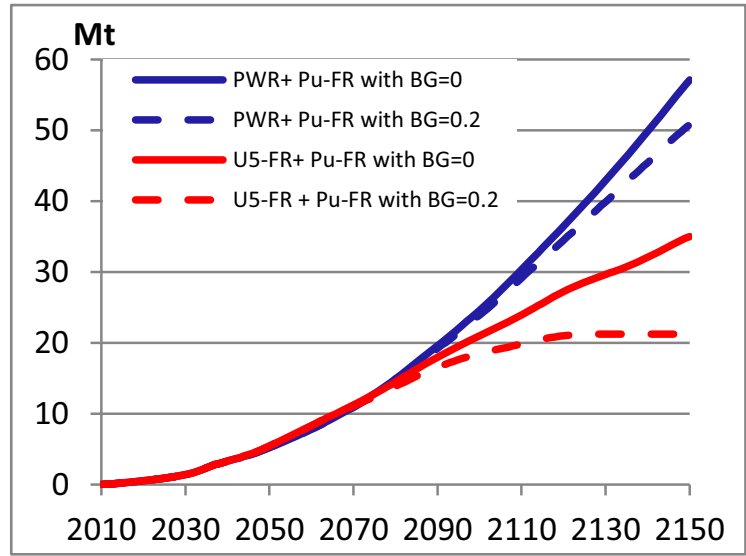

Fig. 2. Scenario A3 - Total consumed $U_{\text {nat }}$.

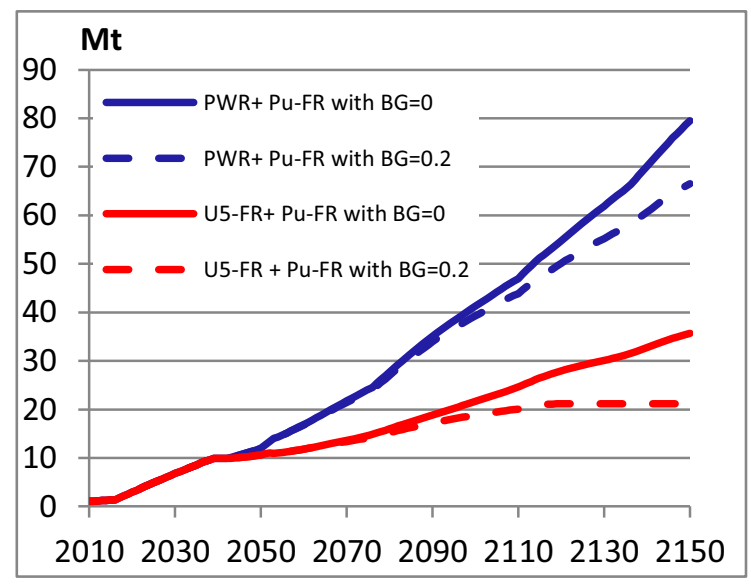

Fig. 3. Scenario A3 - Total consumed + committed $U_{\text {nat }}$. 
Tables 4 to 7 indicate the total consumption of uranium (consumed uranium in bold, consumed + committed uranium in italic) for the four different demand scenarios in 2050, 2100 and 2150.

Regardless of the scenario, in 2050, it is observed that the amount of consumed uranium is slightly greater with U5-FRs than with EPRs (see Sect. 3.1). The excessive consumption for U5-FRs at the start of their service life, compared to EPRs, is thus noted. However, when also considering committed uranium, uranium savings have already been observed.

In 2100, savings start to be significant especially in terms of committed uranium.

In 2150 , a significant decrease in the overall uranium consumption is noted when favouring the development of U5-FRs and in some situations it is even halved. In some

Table 4. $\mathrm{U}_{\text {nat }}$ consumed and committed to scenario A2 in 2050, 2100 and 2150.

\begin{tabular}{|c|c|c|c|c|c|c|}
\hline \multirow[t]{2}{*}{ Scenario A2 } & \multicolumn{2}{|c|}{2050} & \multicolumn{2}{|c|}{2100} & \multicolumn{2}{|c|}{2150} \\
\hline & $\mathrm{GR}=0$ & $\mathrm{GR}=0.2$ & $\mathrm{GR}=0$ & $\mathrm{GR}=0.2$ & $\mathrm{GR}=0$ & $\mathrm{GR}=0.2$ \\
\hline \multirow[t]{2}{*}{$\mathrm{EPR}+\mathrm{Pu}-\mathrm{FR}$} & 2.5 & 2.5 & 20 & 20 & 55 & 51 \\
\hline & 4.7 & 4.7 & 37 & 36 & 80 & 70 \\
\hline \multirow[t]{2}{*}{$\mathrm{U} 5-\mathrm{FR}+\mathrm{Pu}-\mathrm{FR}$} & 2.7 & 2.7 & 16 & 14 & 32 & 19 \\
\hline & 4.6 & 4.6 & 17 & 15 & 32 & 19 \\
\hline
\end{tabular}

Bold: total consumed $\mathrm{U}_{\text {nat }}(\mathrm{Mt})$; italic: total consumed and committed $\mathrm{U}_{\text {nat }}(\mathrm{Mt})$.

Table 5. $\mathrm{U}_{\text {nat }}$ consumed and committed to scenario A3 in 2050, 2100 and 2150.

\begin{tabular}{|c|c|c|c|c|c|c|}
\hline \multirow[t]{2}{*}{ Scenario A3 } & \multicolumn{2}{|c|}{2050} & \multicolumn{2}{|c|}{2100} & \multicolumn{2}{|c|}{2150} \\
\hline & $\mathrm{GR}=0$ & $\mathrm{GR}=0.2$ & $\mathrm{GR}=0$ & $\mathrm{GR}=0.2$ & $\mathrm{GR}=0$ & $\mathrm{GR}=0.2$ \\
\hline \multirow[t]{2}{*}{$\mathrm{EPR}+\mathrm{Pu}-\mathrm{FR}$} & 5.2 & 5.2 & 25 & 24 & 57 & 51 \\
\hline & 12 & 12 & 41 & 39 & 79 & 66 \\
\hline \multirow{2}{*}{$\mathrm{U} 5-\mathrm{FR}+\mathrm{Pu}-\mathrm{FR}$} & 5.4 & 5.4 & 21 & 18 & 35 & 21 \\
\hline & 11 & 11 & 22 & 19 & 36 & 21 \\
\hline
\end{tabular}

Bold: total consumed $\mathrm{U}_{\text {nat }}(\mathrm{Mt})$; italic: total consumed and committed $\mathrm{U}_{\text {nat }}(\mathrm{Mt})$.

Table 6. $\mathrm{U}_{\text {nat }}$ consumed and committed to scenario B in 2050, 2100 and 2150.

\begin{tabular}{|c|c|c|c|c|c|c|}
\hline \multirow[t]{2}{*}{ Scenario B } & \multicolumn{2}{|c|}{2050} & \multicolumn{2}{|c|}{2100} & \multicolumn{2}{|c|}{2150} \\
\hline & $\mathrm{GR}=0$ & $\mathrm{GR}=0.2$ & $\mathrm{GR}=0$ & $\mathrm{GR}=0.2$ & $\mathrm{GR}=0$ & $\mathrm{GR}=0.2$ \\
\hline \multirow[t]{2}{*}{$\mathrm{EPR}+\mathrm{Pu}-\mathrm{FR}$} & 5.0 & 5.0 & 21 & 20 & 47 & 42 \\
\hline & 12 & 12 & 35 & 33 & 64 & 53 \\
\hline \multirow[t]{2}{*}{$\mathrm{U} 5-\mathrm{FR}+\mathrm{Pu}-\mathrm{FR}$} & 5.2 & 5.2 & 18 & 16 & 29 & 18 \\
\hline & 10 & 10 & 19 & 17 & 30 & 18 \\
\hline
\end{tabular}

Bold: total consumed $\mathrm{U}_{\text {nat }}(\mathrm{Mt})$; italic: total consumed and committed $\mathrm{U}_{\text {nat }}(\mathrm{Mt})$.

Table 7. $\mathrm{U}_{\text {nat }}$ consumed and committed to scenario C2 in 2050, 2100 and 2150.

\begin{tabular}{|c|c|c|c|c|c|c|}
\hline \multirow[t]{2}{*}{ Scenario C2 } & \multicolumn{2}{|c|}{2050} & \multicolumn{2}{|c|}{2100} & \multicolumn{2}{|c|}{2150} \\
\hline & $\mathrm{GR}=0$ & $\mathrm{GR}=0.2$ & $\mathrm{GR}=0$ & $\mathrm{GR}=0.2$ & $\mathrm{GR}=0$ & $\mathrm{GR}=0.2$ \\
\hline \multirow[t]{2}{*}{$\mathrm{EPR}+\mathrm{Pu}-\mathrm{FR}$} & 3.5 & 3.5 & 11 & 11 & 22 & 19 \\
\hline & 7.4 & 7.4 & 18 & 16 & 30 & 23 \\
\hline \multirow[t]{2}{*}{$\mathrm{U} 5-\mathrm{FR}+\mathrm{Pu}-\mathrm{FR}$} & 3.7 & 3.7 & 10 & 10 & 15 & 10 \\
\hline & 7.0 & 7.0 & 11 & 10 & 15 & 10 \\
\hline
\end{tabular}

Bold: total consumed $\mathrm{U}_{\text {nat }}(\mathrm{Mt})$; italic: total consumed and committed $\mathrm{U}_{\text {nat }}(\mathrm{Mt})$. 
cases, the quantities of consumed $\mathrm{U}_{\text {nat }}$ and consumed + committed $U_{\text {nat }}$ are identical, which means that no currently operational reactor requires uranium.

We remarked the brief excess consumption of uranium when U5-FRs are deployed rather than light-water reactors (see Fig. 4, example of scenario A3). We wanted to check if this could be penalising in terms of the annual demand, whether for uranium extraction or enrichment.

The brief increase due to the deployment of U5-FRs can be seen in Figure 5 with respect to the uranium demand and in Figure 6 for enrichment needs. It can be seen that the increase is nevertheless reasonable since several U5-FRs are included in the global fleet which is mainly composed of light-water reactors.

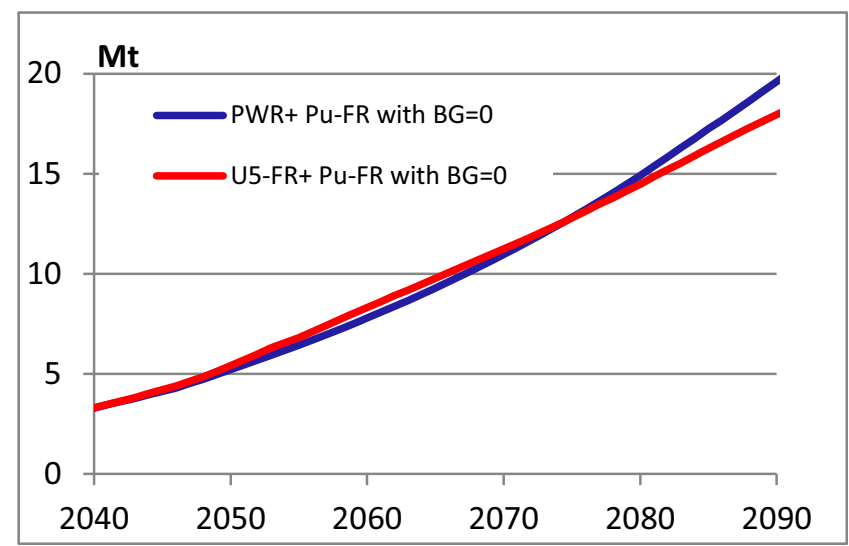

Fig. 4. Scenario A3 - Accumulated consumption of $U_{\text {nat }}$.

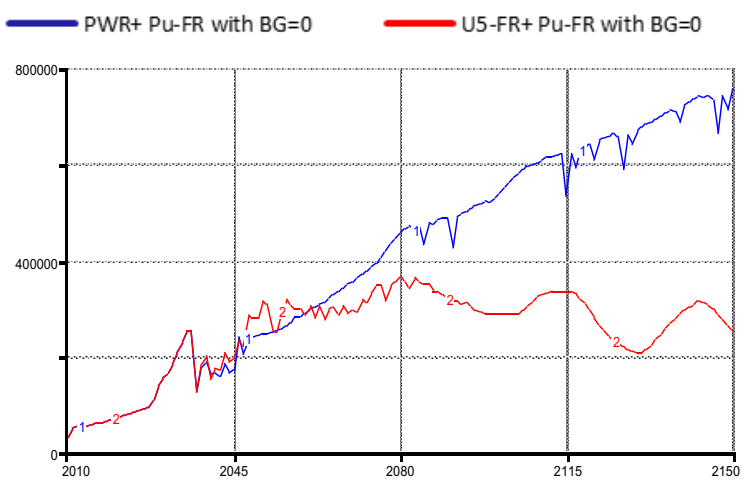

Fig. 5. Scenario A3 - Annual demand for $U_{\text {nat }}$ (in tons).

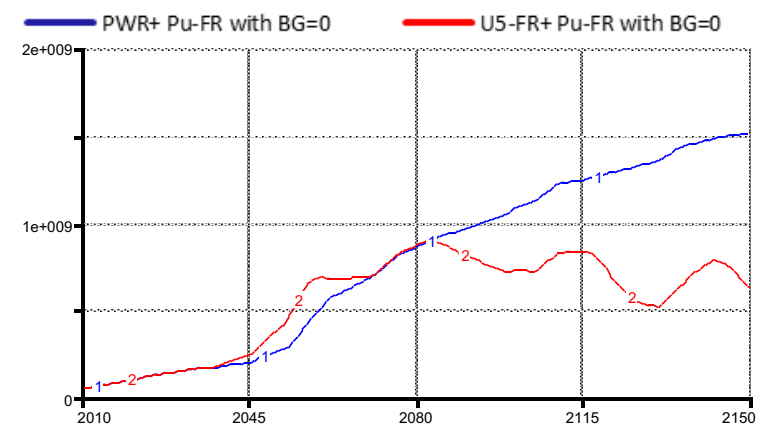

Fig. 6. Scenario A3 - Annual demand for SWU.

\section{Potential nuclear capacity}

Up until now, we have considered it possible to extract the quantity of uranium required as long as the extraction cost is paid. This assumption seems realistic in a market context and it considers that resources diluted in seawater are accessible, though it does not take into account procurement issues which could arise once all conventional resources have been exhausted.

In this section, we approach the issue of resources in a different manner by considering the available quantities of natural uranium as limited.

\subsection{Different available quantities of uranium}

We have considered four different quantities of available natural uranium:

- $10 \mathrm{Mt}$ corresponding to the order of magnitude of identified uranium resources [1]. This case will be in violet on the figures;

- $20 \mathrm{Mt}$ (in green) corresponding to the order of magnitude of conventional resources, added to $4 \mathrm{Mt}$ of uranium extracted from phosphates [10];

- $40 \mathrm{Mt}$ (in orange) corresponding to the order of magnitude of conventional resources, added to about $22 \mathrm{Mt}$ (former estimate of uranium extracted from phosphates);

- $80 \mathrm{Mt}$ (in blue), which takes into account the possibility of mining exploration finding substantial new resources; there is nothing to support this figure which is based on a very optimistic view of a textbook example.

\subsection{Reactor deployment assumptions}

As mentioned in the previous section, Generation IV reactors will be technically available from 2040 .

We have added an extra constraint: when the committed uranium (i.e. taking into account the needs of operational reactors throughout their services lives) exceeds one of the limits in question, it will be impossible to build a new reactor requiring enriched uranium (i.e. PWRs, EPRs and U5-FRs in our case). The only reactors that can be built once this limit has been reached are fast reactors started up with plutonium. Considering that plutonium has to be produced and is not available in unlimited quantities, one day we will no longer be able to build enough reactors and thus no longer match supply to demand.

\subsection{Deployment of EPRs only}

Figures 7 to 10 show the quantity of energy that the nuclear system may produce for each scenario depending on the limits on available uranium quantities.

Demand is indicated in black, while nuclear power generation as a function of the limited quantities of uranium is indicated in colour. 


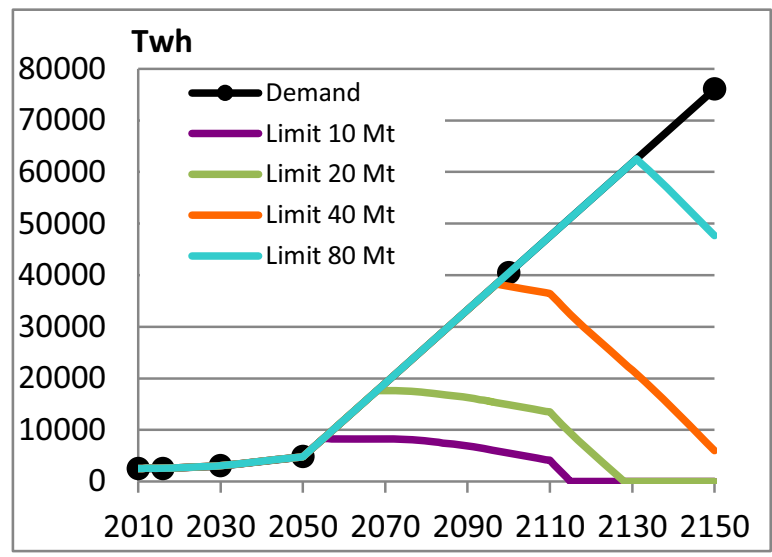

Fig. 7. Scenario A2 - Electronuclear production by PWRs only.

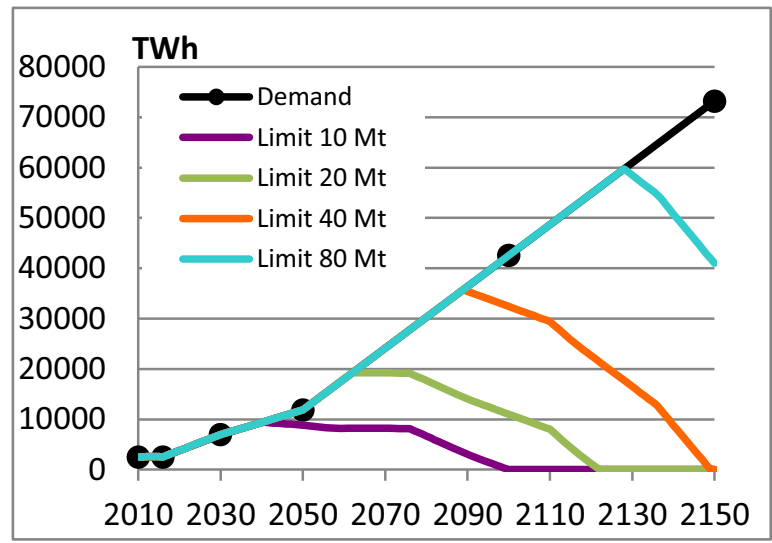

Fig. 8. Scenario A3 - Electronuclear production by PWRs only.

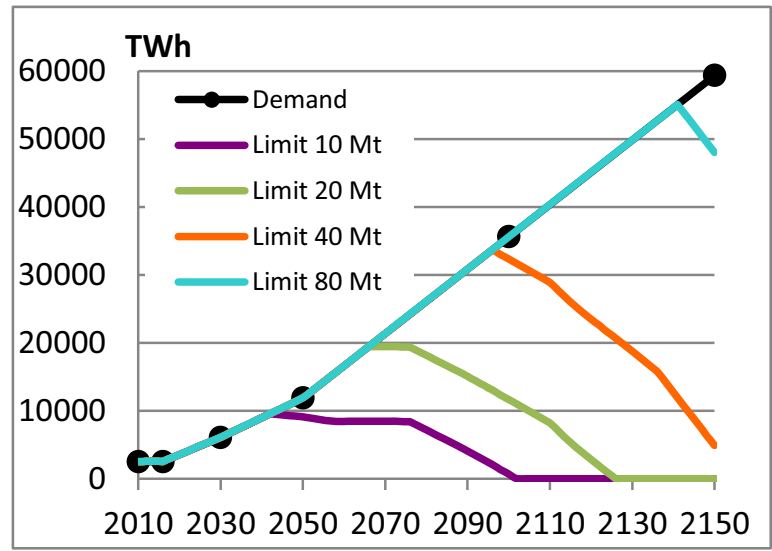

Fig. 9. Scenario B - Electronuclear production by PWRs only.

The different colour curves drop off from the black curve. This moment corresponds to the date at which the uranium limit is equal to the quantity of uranium already consumed, added to the committed quantity for the future operation of reactors already in service.

When nuclear power generation reaches 0 , this limit quantity of uranium has been consumed.

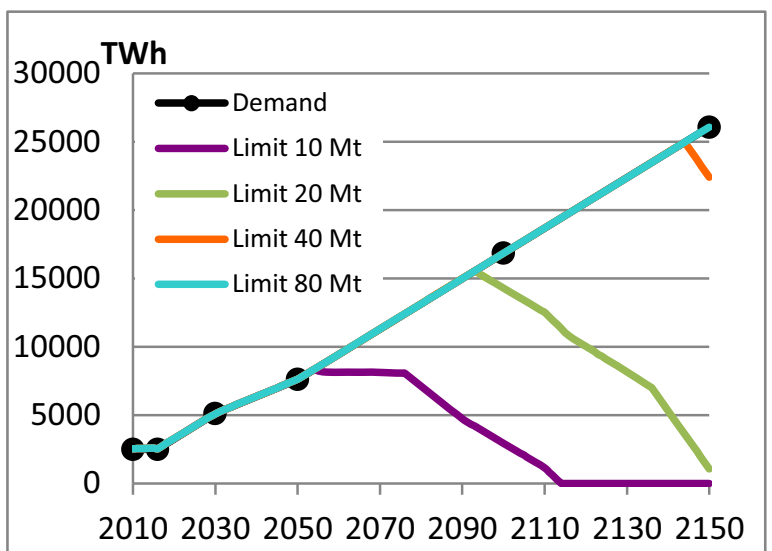

Fig. 10. Scenario C2 - Electronuclear production by EPRs only.

It is clear that nuclear power will not be sustainable with only Generation III reactors. Scenario C2, which requires only $25,000 \mathrm{TWh}$ in 2150 , is the only case where demand could be met despite more than $40 \mathrm{Mt}$ of uranium required (consumed + committed) at this date and already $20 \mathrm{Mt}$ in 2100 .

\subsection{Deployment of self-sufficient or breeder Pu-FRs from 2040}

Since we have shown that only light-water reactors do not meet the nuclear power generation demand as laid out in the prospective scenarios, we included Generation IV reactors from 2040. We considered these reactors with a first fissile $\mathrm{Pu}$ load, which means that $\mathrm{Pu}$ availability will therefore be an important parameter for their deployment.

Figures 11 to 14 show for each scenario the nuclear power generation that can be expected in relation to the type of reactors deployed and as a function of the quantity of uranium believed to be extractable. Just as a reminder, the case with only PWRs is shown by the thin lines. The case with self-sufficient FRs is in solid lines. The case with breeder reactors is in dashed lines.

Contrary to the case where only light-water reactors would be deployed (thin line), here it would be possible to maintain nuclear production regardless of the case considered. Despite this, most of the cases remain far from meeting demand.

It can be seen that an installed power plateau is reached after a certain time with self-sustained reactors (solid lines), which corresponds to the quantity of Pu produced in PWRs based on the available quantity of uranium. This represents a FR installed power capacity of about $70 \mathrm{GWe} / \mathrm{Mt}$ of uranium.

It can also be seen that production is significantly increased with breeder reactors (dashed lines), especially in the next century. Yet more than often, demand is not met.

For the first three high-demand scenarios, about $80 \mathrm{Mt}$ and self-sufficient reactors at least are needed to meet demand. More than $20 \mathrm{Mt}$ is needed with breeder reactors for scenario $\mathrm{C} 2$ which has a lower demand, or slightly more than $40 \mathrm{Mt}$ in the case where only self-sufficient reactors are used. 


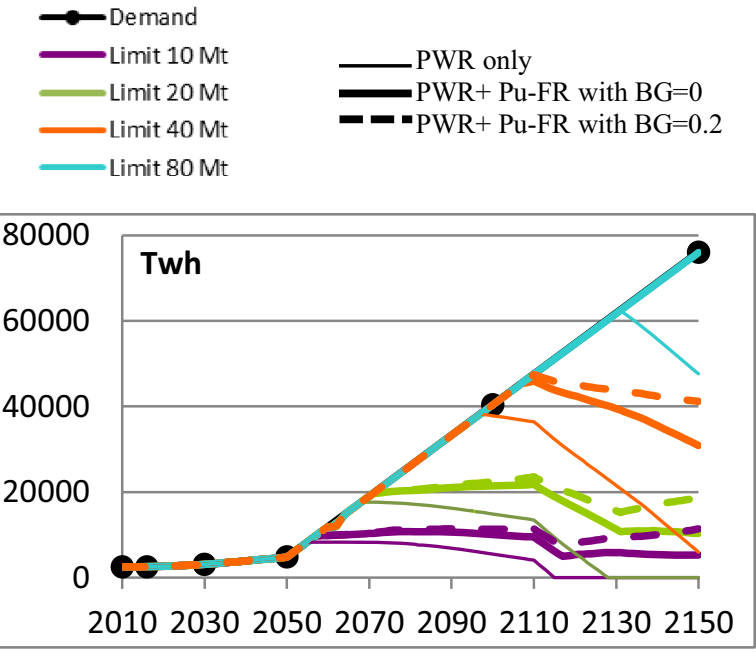

Fig. 11. Scenario A2 - Production by EPRs and Pu-FRs.

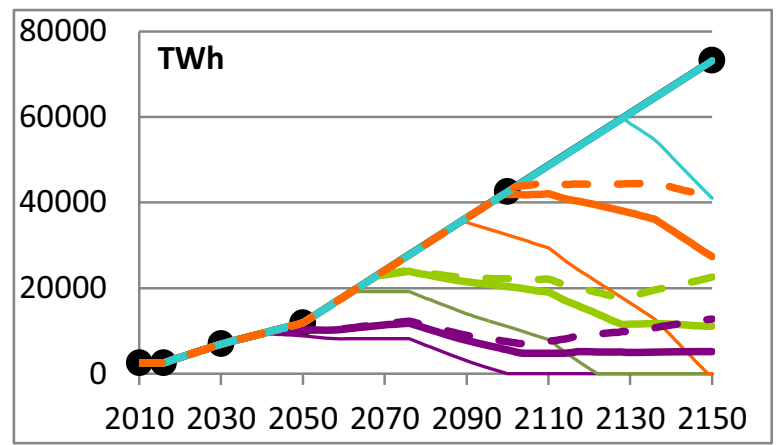

Fig. 12. Scenario A3 - Production by EPRs and Pu-FRs.

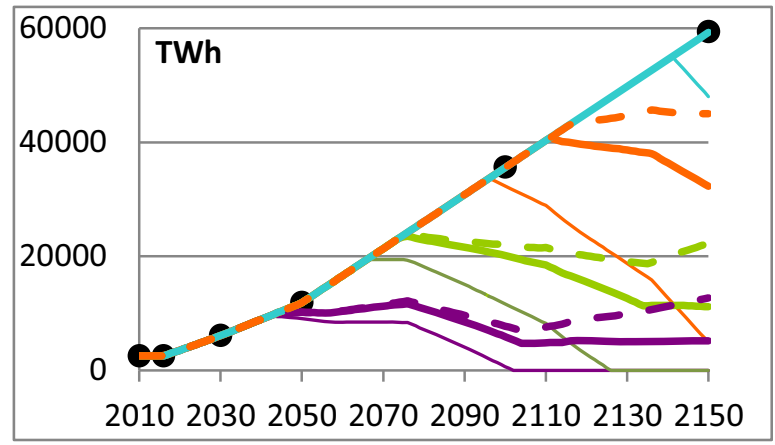

Fig. 13. Scenario B - Production by EPRs and Pu-FRs.

\subsection{Deployment of self-sustaining and breeder Pu-FRs and U5-FRs}

We established in the paragraph above that including FRs was not sufficient to meet the demand in many cases, especially when the uranium quantities were limited $(<80 \mathrm{Mt})$.

We have already shown that a U5-FR consumes three times less natural uranium than an EPR. We also remarked

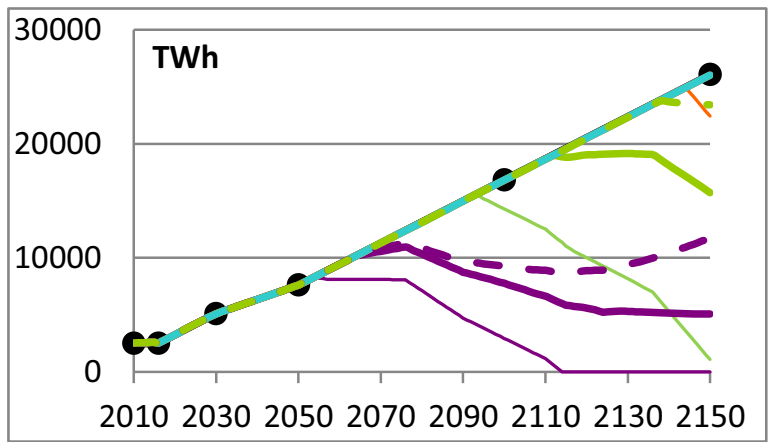

Fig. 14. Scenario C2 - Production by EPRs and Pu-FRs.

that a reactor fleet including the deployment of U5-FRs instead of EPRs made it possible to reduce the accumulated consumption of uranium by two.

Now the objective is to see whether such reactors are capable of meeting the demand despite the limits imposed on the quantities of available uranium.

Technically speaking, these reactors will be available from 2040, as is the case for Pu-FRs. From this date, priority will be given to deploying $\mathrm{Pu}-\mathrm{FRs}$ if $\mathrm{Pu}$ is available, otherwise we will resort to using U5-FRs.

We have restricted ourselves to referring to the curves of the two extreme scenarios (A3 and C2).

On the previous figures, we added the case with FR started with uranium in large full line, and divided the results in several figures (one per limit in uranium) so that it is still readable.

The following conclusions were reached for scenario A3:

- with only $10 \mathrm{Mt}$ of available uranium (Fig. 15), it is practically all consumed before FRs are integrated. The advantage of U5-FRs is therefore insignificant;

- for other uranium limits, particularly 20 and $40 \mathrm{Mt}$ (Figs. 16 and 17), the relevance of deploying U5-FRs rather than EPRs is clearly visible when plutonium is not readily available. If only $20 \mathrm{Mt}$ of uranium is available, then breeder reactors are needed to meet the demand. With $40 \mathrm{Mt}$ of uranium, self-sufficient reactors are adequate to meet the demand;

- if $80 \mathrm{Mt}$ of uranium is available, it has already been seen that $\mathrm{Pu}$-FRs are sufficient to meet the demand (see Fig. 12).

Similar conclusions could be drawn for scenarios A2 and $\mathrm{B}$.

The following conclusions were reached for scenario $\mathrm{C} 2$ :

- as this scenario was generally less ambitious in terms of nuclear power generation, the $10 \mathrm{Mt}$ of uranium was not consumed and committed in 2040. The positive contribution of U5-FRs is thus visible since the demand is met with these reactors when they are in breeder configuration, while remaining below $10 \mathrm{Mt}$ of uranium consumption (Fig. 18);

- when only $20 \mathrm{Mt}$ of uranium is available (Fig. 19), breeder $\mathrm{Pu}-\mathrm{FRs}$ are practically sufficient. Self-sufficient U5-FRs are just barely required; 


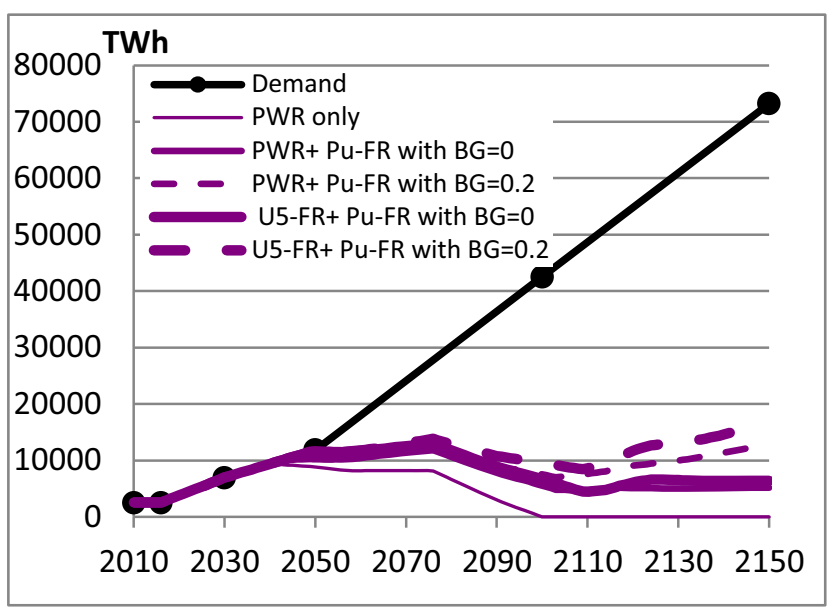

Fig. 15. Scenario A3 with $10 \mathrm{Mt}$ of uranium - Electronuclear production.

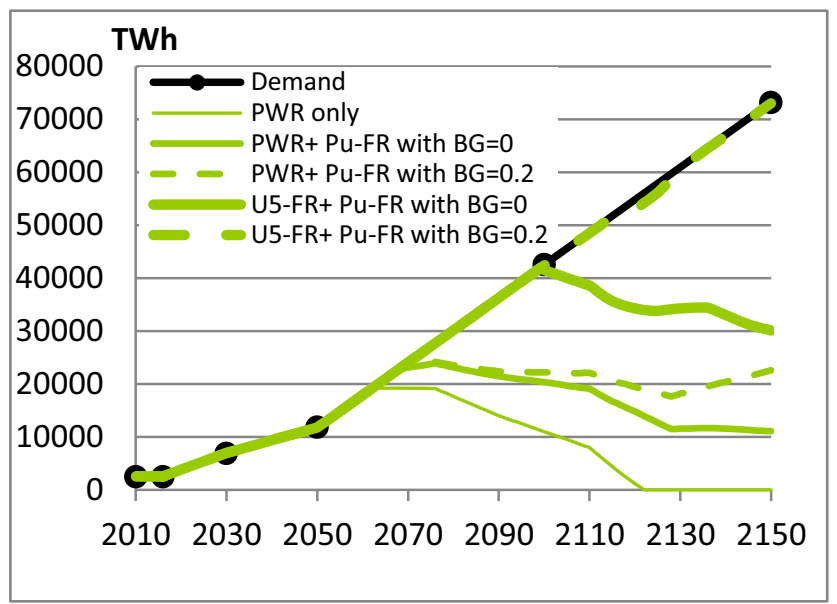

Fig. 16. Scenario A3 with $20 \mathrm{Mt}$ of uranium - Electronuclear production.

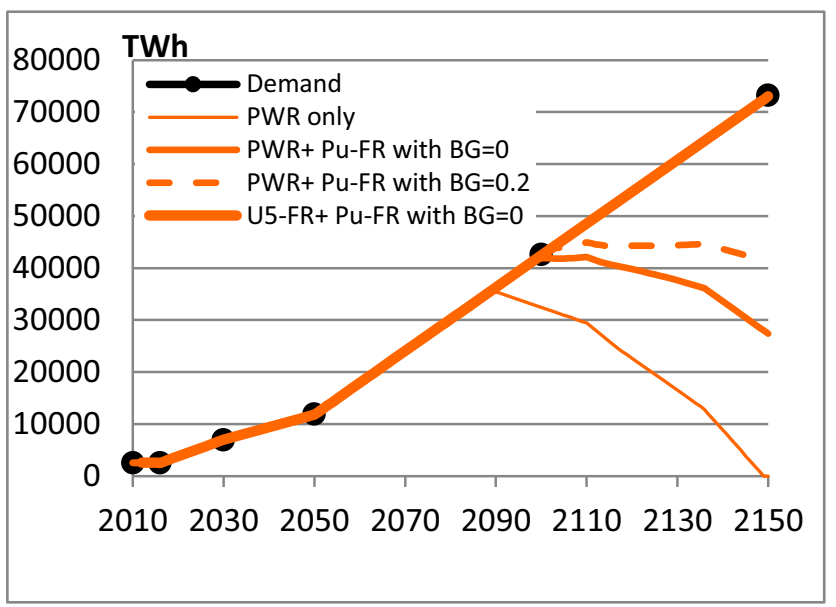

Fig. 17. Scenario A3 with $40 \mathrm{Mt}$ of uranium - Electronuclear production.

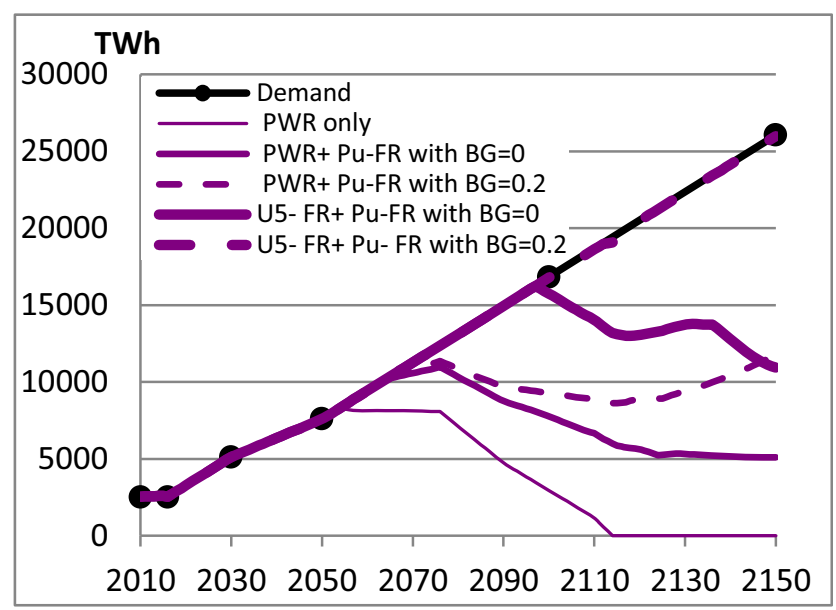

Fig. 18. Scenario C2 with $10 \mathrm{Mt}$ of uranium - Electronuclear production.

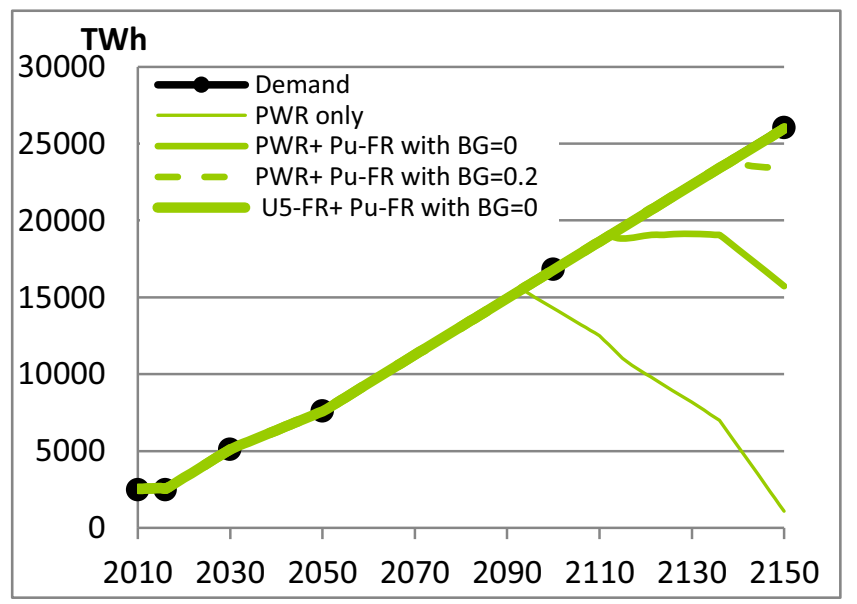

Fig. 19. Scenario C2 with $20 \mathrm{Mt}$ of uranium - Electronuclear production.

- self-sufficient FRs or PWRs were sufficient for 40 and $80 \mathrm{Mt}$ of uranium respectively, as had already been concluded previously (see Figs. 10 and 14).

\section{Conclusion}

The purpose of this study was to determine what types of reactors and fuels would be needed to meet different nuclear power production scenarios.

Nuclear power is not sustainable on the basis of lightwater reactors only, unless the demand remains relatively limited (scenario C2 $=25,000 \mathrm{TWh}$ in $2150 \approx 3000 \mathrm{GWe}$ ) and we have large stocks of available uranium (more than $40 \mathrm{Mt})$. The fourth generation of reactors is therefore essential if we wish to meet demand. Yet, the quantities of available plutonium do not always enable us to deploy as many fast reactors as required and light-water reactors are often necessary to supplement the nuclear reactor fleet to meet the demand. 
Self-sufficient configurations of Generation IV reactors would make it possible to meet scenario $\mathrm{C} 2$ with a uranium consumption of more than $40 \mathrm{Mt}$ all the same. Almost $80 \mathrm{Mt}$ of uranium is required for higher-demand scenarios.

When breeder configurations are applied to Generation IV reactors, only $20 \mathrm{Mt}$ of uranium is required for scenario $\mathrm{C} 2$. The demand will remain partially unmet for the three other scenarios.

We therefore imagined the deployment of fast reactors started up with enriched uranium to remedy the lack of available plutonium. This type of reactor consumes three times less uranium than an EPR-type light-water reactor. We assumed that uranium was only needed for the first core and the first few reloads, but then the plutonium produced by the reactor would be used thereafter.

Thanks to these reactors, the nuclear reactor fleet would be able to meet demand in scenarios A2, A3 and B (from 60,000 to $80,000 \mathrm{TWh}$ in $2150 \approx 7500$ to $10,000 \mathrm{GWe}$ ). These reactors would have to be breeders in the case there is only $20 \mathrm{Mt}$ of uranium, or only self-sufficient with $40 \mathrm{Mt}$ of uranium available.

In the case of only $10 \mathrm{Mt}$ of uranium, these Generation IV reactors - which will be technically available in 2040 will arrive too late since this quantity of uranium will have been consumed prior to this date. It is only scenario $\mathrm{C} 2$ that can be met with U5-FRs in breeder configuration, with $10 \mathrm{Mt}$ of uranium available.

In terms of resource savings, U5-FRs are seen to be the best solution for using limited quantities of uranium while providing maximum nuclear power. Unfortunately, though uranium consumption is three times less for U5-FRs than that for an EPR-type light-water reactor, it is nevertheless consumed at the start of the reactor's life span which represents a significant economic disadvantage. For this reason, economic aspects will hinder the deployment of this type of reactor.

\section{References}

1. OECD/NEA and IAEA, Uranium 2014: resources, production and demand, Report No. 7209, 2014

2. S. Gabriel, A. Baschwitz, G. Mathonnière, F. Fizaine, T. Eleouet, Building future nuclear power fleets: the available uranium resources constraint, Res. Policy 38, 458 (2013)

3. N. Nakićenović, A. Grübler, G. McDonald, Global energy perspectives IIASA/WEC (Cambridge University Press, 1998)

4. Isee Systems, the Visual thinking company: http://www. iseesystems.com/

5. GEN IV international forum, Annual report 2014, Chap. III, 2014

6. H. Safa, P. Dumaz, J.F. Luciani, L. Buiron, B. Fontaine, J.P. Grouiller, Is it worth to start fast reactors using uranium fuels, in ICAPP 2011: International Congress on Advances in NPPs "Performance $\&$ Flexibility: The Power of Innovation", Nice, France (2011)

7. A. Baschwitz, G. Mathonnière, S. Gabriel, Economic relevance of starting an SFR with enriched uranium, in FR13: International Conference on Fast Reactors and Related Fuel Cycles: Safe Technologies and Sustainable Scenarios, Paris, France (2013)

8. A. Baschwitz, C. Loaëc, J. Fournier, M. Delpech, GEN IV deployment: long-term perspective, in FR09: International Conference on Fast Reactors and Related Fuel Cycles: Challenges and Opportunities, Kyoto, Japan (2009)

9. A. Baschwitz, C. Loaëc, J. Fournier, M. Delpech, F. Legée, Long-term prospective on the electronuclear fleet: from GEN II to GEN IV, in Global 2009: The Nuclear Fuel Cycle: Sustainable Options $\&$ Industrial Perspectives, Paris, France (2009)

10. S. Gabriel, A. Baschwitz, G. Mathonnière, T. Eleouet, F. Fizaine, A critical assessment of global uranium resources, including uranium in phosphate rocks, and the possible impact of uranium shortages on nuclear power fleets, Ann. Nucl. Energy 58, 213 (2013)

Cite this article as: Anne Baschwitz, Gilles Mathonnière, Sophie Gabriel, Tommy Eleouet, Deployable nuclear fleet based on available quantities of uranium and reactor types - the case of fast reactors started up with enriched uranium, EPJ Nuclear Sci. Technol. 2, 12. (2016) 